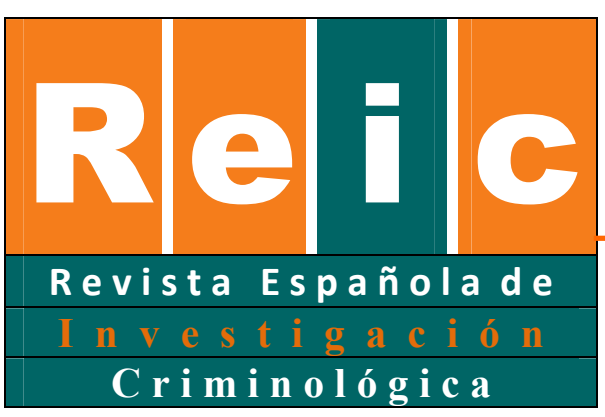

\title{
Public Criminology?
}

de Ian Loader y Richard Sparks. London: Routledge. (2010)

Por una criminología al servicio

de la democracia

Juanjo Medina

School of Law

University of Manchester

\section{Los argumentos}

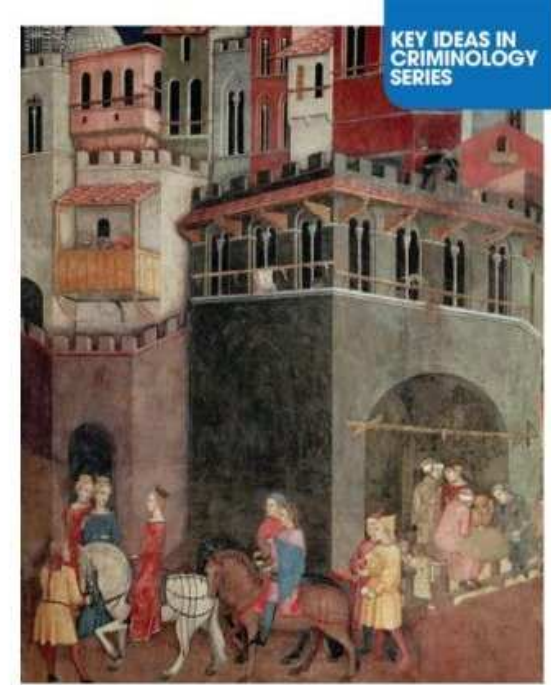

PUBLIC CRIMINOLOGY?

IAN LOADER AND RICHARD SPARIKS

La última década ha sido testigo de lo que en el ámbito anglosajón algunos han caracterizado como la paradoja del éxito de la criminología. Mientras que nuestra disciplina se ha institucionalizado más solidamente en el ámbito científico y universitario, a nivel social y político hemos asistido a una serie de desarrollos que han limitado el peso de la evidencia científica a la hora de desarrollar políticas de control de la delincuencia mientras que el calculo electoral demagógico ha contribuido a aprobar medidas penales cada vez más excluyentes, intrusivas y represivas. El problema de la desconexión entre ciencia y política no es exclusivo de la criminología. Otras ciencias sociales se encuentran con problemas similares. En este sentido, el sociólogo Michael Buraway, en su discurso inaugural como presidente de la American Sociological Association, reinició un debate en esta disciplina sobre cuál ha de ser el papel del sociólogo frente a estas nuevas dinámicas sociales por medio del desarrollo de la noción de una "sociología pública" que servía para 
demandar una mayor papel del sociólogo en la vida pública y política. En este libro sobre "criminología pública" Ian Loader y Richard Sparks emplean esta idea como punto de partida y problematizan tanto la presunta paradoja del éxito de la criminología, en el capitulo primero, como el concepto de sociología pública propuesto por Buraway, en el capítulo segundo, para discutir de forma especifica la relación entre política y ciencia en el ámbito de la criminología.

Loader y Sparks producen una narrativa del desarrollo de las diversas escuelas y posicionamientos criminológicos en los últimos 30 años que gira en torno a su conexión con el mundo de la política y la forma que han respondido a lo que estos autores denominan como el, bien documentado, 'calentamiento global' de los discursos públicos sobre delincuencia y justicia penal. En este sentido es una obra de utilidad para entender el posicionamiento político de diversas corrientes criminológicas. Para estos autores, sintetizando mucho se pueden describir cinco actitudes básicas tomadas por los criminólogos en la esfera pública, cinco actitudes que suelen encontrar mayor o menor recepción por parte de determinadas escuelas criminológicas según el caso. Estas actitudes corresponderían a la posición del criminólogo como:

- Experto científico (por ejemplo, los investigadores asociados a la Colaboración Campbell, cuyo representante español es Vicente Garrido, o los partidarios de la ciencia del delito), que considera que su papel consiste en producir conocimiento científico sobre la criminalidad y los programas que pueden funcionar para controlarla para que la sociedad pueda emplear recursos limitados de forma eficiente.

- Consultor político (por ejemplo, autores como Joan Petersilia, Hans Boutellier, Allison Liebling, o Neils Christie), que considera que su papel consiste fundamentalmente en asegurarse, trabajando detrás de la escena, que la clase política recibe consultorías e información adecuadas en materia de seguridad y justicia penal.

- Observador que decide saltar a la política (en el caso británico tendríamos autores como Paul Wiles, Betsy Stanko o Rod Morgan mientras que en España podríamos destacar a Esther Giménez o a Santiago Redondo en su época al frente de la administración penitenciaria catalana), que considera que la única forma de que la investigación criminológica influya la agenda política es por medio de implicarse ellos mismos en el proceso político, por ejemplo, aceptando cargos de responsabilidad política o administrativa.

- El activista o teórico de los movimientos sociales (desde Stanley Cohen, John Braitwaite, Thomas Matiesen, Clifford Shearing, John Hagedorn, mientras que en España habría que destacar a autores como Roberto Bergalli y sus colaboradores), que considera que el papel de la criminología ha de ser el de desarrollar discursos críticos alternativos al servicio de los más marginados frente a las posiciones oficiales en materia de seguridad.

- El profeta solitario (David Garland, Jonathan Simon, Loic Wacquant, Richard Ericson, mientras que en España podríamos destacar el trabajo de autores como José Luis Díez Ripollés o Jesús María Silva), que está particularmente interesado en los grandes debates sobre fuerzas culturales y sociales a nivel 
macro y global, y la forma que estos influyen el desarrollo local de las respuestas penales.

El problema para Loader y Sparks es que estas posiciones típicas, no solamente representan formas de participar en la vida pública sino que se emplean demasiado a menudo como puntos de vista y creencias vitales, posiciones con las que uno se identifica y a las que uno pertenece, como un "inventario de las cosas que se pueden o no se pueden decir o hacer, con el consiguiente reparto de héroes y villanos" (Loader y Sparks, 2010: 36). En ese sentido destacan que las mismas consagran el estado actual de la criminología en la que, frente al dialogo constructivo entre distintas escuelas, la pluralidad de perspectivas criminológicas se enfoca como problema por medio de la institucionalización de diferencias que consagran la creencia de que la posición que uno adopta es mejor que todas las demás y que los demás deberían adoptarla también.

De hecho, estos autores encuentran un paralelismo importante entre estas posiciones y la actitud de diversas escuelas frente a la politización de la cuestión penal, el referido calentamiento de la cuestión penal. Loader y Sparks (2010) consideran de utilidad y necesario el discurso de "los profetas solitarios" en entender las fuerzas que han contribuido a este calentamiento (de hecho habría quien posiblemente usaría tanto a Loader como a Sparks como autores que han actuado en ocasiones como profetas solitarios), si bien encuentran este discurso limitado en cuanto a la proposición de posiciones políticas más concretas y menos insulares. Por otro lado, destacan como la criminología radical y crítica que surge en la década de los 70 también contribuyó a este calentamiento de la cuestión penal al destacar que la definición de la criminalidad es un proceso ineludiblemente político que hay que resistir o apoyar, según la causa. Como Loader y Sparks (2010) la criminología crítica interpreta la delincuencia y el control social "como cosas que contienen o generan calor" (en el indicado sentido metafórico) "al que hay que dar un cauce adecuado, o incluso a veces inflamar" y es un calor que "ni puede apagarse, ni puede ser ignorado". Este último aspecto, es algo con lo que Loader y Sparks (2010) muestran un acuerdo absoluto: por más que nos moleste que la cuestión penal se haya "politizado" no cabe la menor duda de que la delincuencia y el control de la misma son cuestiones políticas por excelencia y, por tanto, la forma en la que los criminólogos aspiren a dar respuesta en el nuevo contexto económico y social a la cuestión de cómo deben participar en la vida pública y relacionarse con el mundo de la política ha de partir de esta asunción básica.

Es precisamente este convencimiento el que conduce a Loader y Spark (2010) a criticar cuatro respuestas diferentes que se han dado desde el mundo de la criminología (y sus disciplinas parejas) al "problema" de la "politización" de la cuestión penal. Loader y Sparks caracterizan a estas respuestas como intentos de "enfriar" (y en ocasiones despolitizar) la cuestión penal por medio de la defensa del principio de legalidad, la defensa de una política basada en la evidencia científica ligado a ambiciosos programas de evaluación de políticas públicas, el desarrollo de técnicas situacionales de control de la delincuencia, o la creación de instrumentos políticos y burocráticos para reducir el peso del populismo político en materia penal.

Aunque Loader y Spark comparten con los proponentes del garantimos penal, de un derecho penal mínimo, y otros campeones de los derechos civiles la preocupación 
por el continuo retroceso en esta materia, consideran que estas posiciones a menudo tan solo plantean una forma negativa de hacer política, el liberalismo del miedo, que a veces parece más interesado en mantener el status quo que en pensar de forma rigurosa sobre algunas de las nuevas amenazas en materia de seguridad. Sobre estas cuestiones Ian Loader ya había desarrollado un argumento más complejo en su libro Civilizing Security (2007) junto al profesor Neil Walker.

A los campeones de la política basada en la evidencia científica, particularmente al modelo de la Colaboración Campbell critican su fundamentalismo metodológico obsesionado con el experimento clásico y los meta-análisis; su visión ingenua del mundo de la política; y sus esfuerzos por sustituir el proceso político por cálculos 'racionales', institucionalizados en consejos nacionales de prevención, que solamente son neutrales en apariencia. De acuerdo con este modelo lo que habría que hacer sería crear comités de expertos que trazaran el camino a seguir en materia política criminal sobre la base de investigación evaluativa, en lugar de dejar estas cuestiones en manos de los políticos. De acuerdo con Loader y Sparks este es un modelo elitista que parece proponer la superioridad de los hechos científicamente probados sobre los juicios basados en valores políticos, que parece conceptuar al político no como un representante de los intereses de sus votantes sino como un aplicador de la ciencia social y, sobre todo, que no confronta de forma directa cuestiones normativas (sobre qué valores han de predominar en una sociedad dada).

Este último alegato también les sirve para cuestionar la posición de la "nueva ciencia del delito", institucionalmente enmarcada en el Jill Dando Institute (University College London) y que aglutina a los proponentes de las teorías de la oportunidad criminal (Felson, Clarke, etc.), en su énfasis por desdramatizar y despolitizar la cuestión penal y su afán en proponer, como una forma de tecnocracia liberal antipenal, mecanismos situacionales para prevenir el delito. Como Loader y Sparks señalan no solamente es importante prevenir la delincuencia sino cómo se previene la delincuencia de una forma ética y responsable, una consideración que casi siempre suele estar ausente en las contribuciones desde la nueva ciencia del delito.

Finalmente, aunque comparten con autores como el politólogo Philip Pettit la opinión de que quizás hay que crear espacios institucionales y desarrollar culturas profesionales que medien la relación entre opinión pública y clase política en el ámbito penal, no comparten el diagnostico tan pesimista ni soluciones que consideran insuficientemente democráticas, al pretender dejar el debate de la cuestión penal a profesionales y burócratas (de la misma forma que se deja, por ejemplo, a los bancos centrales las decisiones sobre el tipo de interés bancario).

Para Loader y Sparks no queda más remedio que reconocer el carácter esencialmente político de la delincuencia y ello significa que los debates sobre la misma y su control juegan y han de jugar un papel importante en la vida pública. Se trataría no tanto de tratar de esquivar el proceso político, por medio de la sustracción de la cuestión penal a los políticos, sino de ponerse al servicio del mismo y tratar de enriquecerlo. Igualmente consideran que si queremos desarrollar un debate sobre el papel social de la criminología tenemos que partir de la premisa de celebrar la diversidad y el pluralismo teórico, epistemológico e incluso ideológico de esta disciplina. Adoptar posiciones de escuela en guerra o indiferentes entre sí se considera como un camino sin salida que conduce al empobrecimiento de la disciplina. En este 
sentido estos autores no cuestionan per se, la validez de las distintas corrientes criminológicas examinadas, pero si cuestionan el modelo de relación con la política que unas y otras plantean.

Estos autores creen que una buena forma de concebir el papel social del criminólogo es como la de un trabajador al servicio de la democracia. Para ellos esto significa no solamente trabajar por una política (como resultado) mejor, sino también por una política (como proceso) más rica, dialogante y democrática. Ello requeriría que los criminólogos mejoren su limitado conocimiento de las dinámicas y las patologías del campo de la política (por ejemplo estudiando el proceso político dentro de los grados en criminología) y que aspiren a participar en el de forma más creativa e innovadora. No se trataría de proponer la creación de consejos científicos que sustraigan el debate sobre la cuestión penal de la vida pública sino de desarrollar formas de enriquecer el debate público sobre la delincuencia sin ignorar que discusiones sobre la cuestión penal son siempre discusiones sobre cuestiones más amplias (sobre qué constituye una buena sociedad). Es decir se trataría de apostar no por una política (como resultado) apoyada en (y dirigida por) la evidencia, sino por un proceso político dialogante, democrático e "inteligente" (es decir informado). Sin embargo, en esto coincidiendo con las posiciones más en línea con la postura del "experto científico", consideran que los criminólogos intervienen en el debate público como portadores e intérpretes del conocimiento científico sobre la cuestión delictiva y que estas son intervenciones, por tanto, que han de estar siempre regidas por lo que ellos denominan una "vocación formativa", es decir, la retención de una motivación primordial en la producción de conocimiento, por encima de otro tipo de consideraciones políticas o ideológicas, así como el sometimiento a las reglas del juego científico (por ejemplo, evaluación de pares). Eso no significa la ausencia de un momento crítico (incluso radical) en el desarrollo del conocimiento del conocimiento criminológico, sino más bien el reconocimiento de que "no se ha de repetir el error de muchos intelectuales públicos, que tienen mucho de público y poco de intelectuales". En particular destacan como una de las virtudes de operar desde esta vocación formativa, sobre todo cuando está alojada institucionalmente en entidades de investigación autónomas, es el poder participar en el debate público con una capacidad de libertad que otros actores políticos no tienen (por ejemplo, por estar sometidos a la disciplina del voto).

Es, en definitiva un buen libro de lectura recomendada a quienes estén preocupados por la función social de la criminología y por el creciente populismo punitivo. Entre otras virtudes es un libro escrito con la elegancia, sutileza y sofisticación que suele caracterizar a los buenos académicos británicos y que emplea una bibliografía muy actualizada y útil para el investigador en la materia. El tratamiento de la cuestión es original, y la lectura amena y claramente enriquecedora. El tono generalmente menos cínico y un tanto más utópico, en el buen sentido de la palabra, que otras contribuciones recientes, que no por ello son menos interesantes, al debate sobre el papel social del criminólogo. Al docente español en los grados de criminología, secciones del libro le serán de utilidad a la hora de enmarcar e interpretar el programa político de distintas corrientes criminológicas contemporáneas, así como material que sirva al alumno para reflexionar sobre la función social de la criminología, por tanto puede ser relevante como material suplementario de lectura 
tanto en cursos de teoría criminológica como en cursos de política criminal. Quizás una de las cosas que personalmente me sorprendió, y defraudo, fue la ausencia de ningún tipo de referencias a un particular cuerpo de estudios y publicaciones relevantes para este debate en la sociología de la ciencia. Aunque, como Loader y Sparks señalan, de forma adecuada, que muchos debates no son específicos de la criminología, dejan al margen de su discusión las muy influyentes tesis de autores como Michael Gibbons y Helga Nowotny (Nowotny, Scott, Gibbons, 2001) sobre los nuevos modelos de producción de conocimiento científico y la articulación de la relación entre sociedad, políticos y científicos que se deriva de ellos, así como los paralelos debates en materia de transdicisplinariedad. Hubiera sido interesante de qué forma el criminólogo como trabajador al servicio de la democracia es conceptuado por Loader y Sparks en relación con las propuestas y modelos (claramente normativos y prescriptivos) de estos autores.

El tratamiento de Loader y Sparks, por otro lado, está muy claramente vinculado a la situación política en el Reino Unido. La criminología, como otras ciencias sociales, sigue sufriendo, como el propio Burawoy ha reconocido en numerosas ocasiones, de un notable provincianismo con el que quienes no vivimos en el contexto anglosajón nos tenemos que acostumbrar y que en el contexto internacional conduce al olvido de las particularidades de la periferia (Medina, 2011). Pero ello no significa que las reflexiones de Loader y Sparks no tengan una cierta relevancia para el caso español. En nuestro país se ha documentado también el 'calentamiento global' de los discursos políticos sobre delincuencia, por más que en un modelo 'glocal' este ha reproducido las presiones macroestructurales de la modernidad tardía de forma singular y específica (Medina, 2006). Como respuesta a ello autores vinculados a la Colaboración Campbell en nuestro país han planteado soluciones similares a las propuestas por este colectivo, mientras que desde el derecho penal, en líneas generales, se ha seguido insistiendo en la necesidad de defender el garantismo, el principio de intervención mínima y prácticas penales que no generen exclusión social (reivindicaciones que ya se hacían cuando yo era un estudiante de licenciatura hace más de 15 años y antes de la aceleración de estas tendencias en nuestro país y, por tanto, se podría decir que con bastante poco éxito). De forma más concreta, por tanto, autores como Díez Ripollés (2004: 34) han defendido, entre otras medidas, la necesidad de que "los colectivos y agentes sociales contrarios al modelo de la seguridad ciudadana" (incluyendo se entiende los científicos sociales y juristas académicos) "se organicen en grupos de presión" y que hay que abandonar concepciones ingenuas de que la "racionalidad se impone por sí sola". En otros ámbitos, como el de política económica, profesores universitarios han sabido ciertamente darle una mayor visibilidad a algunas de sus propuestas (ver por ejemplo el trabajo de los economistas ligados a FEDEA y el blog "Nada Es Gratis"). Un ejemplo de estos grupos de presión en el ámbito político criminal es la plataforma "Otro Derecho Penal es Posible". Y si bien es cierto que algunos de estos grupos en el ámbito penal representan una actitud más comprometida, también es cierto que como grupos de presión aun tienen mucho que aprender sobre cómo se estructura y funcionan de forma más efectiva y eficiente los grupos de presión.

Es precisamente en este contexto en el que contribuciones como las de los profesores Loader y Sparks, y las de otros autores que también contribuyen a este 
debate de forma un tanto más cínica y pesimista (ver, por ejemplo, Rocks, 2010), son particularmente relevantes en cuanto que permiten un enfoque más reflexivo, y por tanto más anclado en las virtudes intelectuales académicas, sobre de qué forma se puede articular la presencia del investigador criminológico en el debate público sobre la cuestión penal y permiten también entender de forma más considerada los distintos peligros y vicios asociados con distintas formas de articular dicha presencia.

\section{Referencias}

Díez Ripollés, Jose Luís. 2004. El nuevo modelo penal de la seguridad ciudadana. Revista Electrónica de Ciencia Penal y Criminología. 06(03):1-34.

Medina Ariza, Juan José. 2006. The Politics of Crime in Spain, 1978-2004. Punishment and Society 8(2):183-201.

Medina Ariza, Juan José. 2011. 'Doing criminology in the semi-periphery and the periphery: in search of a postcolonial criminology' en Smith, Zhang y Barberet (eds.). Handbook of International Criminology. Routledge.

Nowotny, Helga, Scott, Peter y Gibbons, Michael. 2001. Rethinking Science: Knowledge and the Public. Polity Press.

Rock, Paul. 2010. Comment on 'Public Criminologies'. Criminology and Public Policy. 9(4): 751-767. 